\title{
Patient satisfaction with pharmaceutical care delivery in community pharmacies
}

\author{
This article was published in the following Dove Press journal: \\ Patient Preference and Adherence \\ 17 April 2012 \\ Number of times this article has been viewed
}

\author{
Rosemin Kassam' \\ John B Collins ${ }^{2}$ \\ Jonathan Berkowitz ${ }^{3}$ \\ 'School of Population and Public \\ Health, Faculty of Medicine, \\ ${ }^{2}$ Department of Educational Studies, \\ Faculty of Education, ${ }^{3}$ Sauder \\ School of Business, University of \\ British Columbia, Vancouver, British \\ Columbia, Canada
}

Background: The purpose of this study was to validate previously published satisfaction scales in larger and more diversified patient populations; to expand the number of community pharmacies represented; to test the robustness of satisfaction measures across a broader demographic spectrum and a variety of health conditions; to confirm the three-factor scale structure; to test the relationships between satisfaction and consultation practices involving pharmacists and pharmacy students; and to examine service gaps and establish plausible norms.

Methods: Patients completed a 15-question survey about their expectations regarding pharmaceutical care-related activities while shopping in any pharmacy and a parallel 15 questions about their experiences while shopping in this particular pharmacy. The survey also collected information regarding pharmaceutical care consultation received by the patients and brief demographic data.

Results: A total of 628 patients from 55 pharmacies completed the survey. The pilot study's three-factor satisfaction structure was confirmed. Overall, satisfaction measures did not differ by demographics or medical condition, but there were strong and significant store-to-store differences and consultation practice advantages when pharmacists or pharmacists-plus-students participated, but not for consultations with students alone.

Conclusion: Patient satisfaction can be reliably measured by surveys structured around pharmaceutical care activities. The introduction of pharmaceutical care in pharmacies improves patient satisfaction. Service gap details indicated that pharmacy managers need to pay closer attention to various consultative activities involving patients and doctors.

Keywords: patient expectations, patient experiences, advanced pharmacy practice experience, medication management

\section{Introduction}

Schools of pharmacy throughout Canada and the United States have made considerable progress in incorporating the philosophy and practice of pharmaceutical care (PC) into their curricula. ${ }^{1,2}$ A key curricular reform has been to recruit experiential sites that support the integration of students into direct patient care activities, thereby enabling cultivation of PC competencies and confidence. The PC process commonly includes conducting assessment of patients' medical concerns as part of new/refill prescription intake; nonprescription consultations; sit-down consultations for chronic diseases; performing individualized medication reviews; developing care plans; providing patient specific interventions; collaborating with other health professionals when necessary; and monitoring patients' progress through follow-up care to ensure desired outcomes are achieved. ${ }^{1-3}$
Correspondence: Rosemin Kassam Faculty of Medicine, School of Population and Public Health, Room 265, 2206 East Mall, Vancouver, British Columbia, Canada V6T IZ3 $\mathrm{Tel}+\mathrm{I} 604822718 \mathrm{I}$

Email rosemin kassam@ubc.ca 
Several studies have demonstrated that providing PC at community pharmacies has significant benefits to patients, and that student involvement extends these benefits to wider patient populations who otherwise would not receive them. ${ }^{3-12}$ Despite these advantages, the dissemination of PC services across community pharmacies in North America has been slow. ${ }^{13-15}$ One proposed approach to stimulate this transition is to quantify patient expectations and current satisfaction with such services. ${ }^{16,17}$ As part of this initiative, a three-phase study was initiated to: first, operationalize patient satisfaction with PC for community pharmacy-based advance pharmacy practice experiences (APPE); second, evaluate the impact of two community pharmacy-based APPE models on patient satisfaction; and third, validate the findings using larger and more diverse patient populations frequenting different varieties of community pharmacies. The results of these first two phases have been published elsewhere. ${ }^{18,19}$ This study aimed to address the third phase.

Various approaches to patient satisfaction resulting from community pharmacy experience have been identified and reviewed elsewhere..$^{20}$ Notable among these are Gourlay's ECHO model, Oliver's pleasurability index, and MacKiegan and Larson's two-factor model. ${ }^{21-23} \mathrm{~A}$ previously published paper has outlined the development of a patient satisfaction scale based on the Hepler and Strand PC framework. ${ }^{3}$ In that pilot study, patient satisfaction was operationalized around PC processes and activities encountered in the community pharmacy setting, then analyzed for validity and psychometric robustness. The scale was based on what patients report actually experiencing during the particular in-store experience contrasted against what they would expect to receive "in any pharmacy anywhere". Patient responses showed clear distinctions between their expectations about PC-related transactions in any store versus their specific experiences with the processes and activities in this particular store. Further, factor analysis indicated that patients' conceptualization of satisfaction focused on three themes, ie, monitoring strategies for medication outcomes, providing information and education, and providing personalized collaborative and preventive care. Because the original pilot study had established the feasibility of conceptualizing and measuring patient satisfaction in community pharmacies in terms of foundational notions of $\mathrm{PC}$ for both pharmacists and their patients, further development and scale validation needed to move beyond the proof-of-concept stage. Generalizability theory offered a convenient logical platform. ${ }^{24}$

To move beyond the proof-of-concept stage, a broader and much larger follow-up study was undertaken with the following five objectives: to test further previously benchmarked satisfaction scales with much larger and more diversified audiences and expanded numbers of national pharmacy chains represented; confirm the pilot study's three-factor structure of PC-based patient satisfaction; verify robustness of satisfaction scales among patients in a wider variety of pharmacies, across a broader range of patient demographics, and across a broad variety of disease types; test the relationships between "consultation intensiveness" and satisfaction with both pharmacist consultations and consultations with students on rotation; and document the range of "service gaps" (differences between what patients expect and what they experience) among the various pharmacies in order to provide managers with tangible information about how to increase patient satisfaction.

\section{Theoretical framework}

Generalizability theory as initially outlined by Cronbach et al is a statistical framework for conceptualizing, investigating, and designing reliable observations. ${ }^{24}$ It is used to determine the reliability (ie, reproducibility) of measurements under specific conditions. For any measuring scale or device to be robust or trustworthy, it must perform consistently across different "facets" - variations in person, item, or occasion $(p, i, o)$ which account for who is responding $(p)$, which scale items are chosen (i), and on which occasions the measurements are taken (o). In short, the scale must be generalizable. In this larger-scale investigation, different and more varied facets were tested; different stores, different retail chains, different times and locations, wider varieties of medical conditions, and broader ranges of patient demographics, ie, gender, age, education, and income, but all with a view toward verifying the generalizability of a PC interpretation of satisfaction.

\section{Overview}

The overall goal of this study was to demonstrate that brief in-store surveys can provide store managers with tightly focused information to improve PC-based direct care to patients during the brief time they are transacting their business with pharmacists, APPE students, and other store personnel. To do that, the robustness and sensitivity of the survey needed to be first solidly documented. Thus, we report initially on our methods, participants, data collection strategies, and analysis procedures. Next, we report results concerning the new participant cohort, anchored scale details, factorial corroboration, the robustness of the satisfaction scales against potentially spurious demographic 
distractors, and finally we report on its sensitivity to the store-to-store differences encountered in field settings. Among those in-store differences are varying practices about structured consultations with patients regarding potential health issues... an essential requisite of true PC-based practice and a central instance of delivery of direct patient care. Lastly, we report on how service gaps detract from true PC and direct care delivery. We discuss how such scales can focus store managers' attention to critical shortfalls in their in-store practices and we conclude with observations about how APPEs and clerkship students can be effective tools for managers to implement fully fledged PC among their stores' personnel and practices.

\section{Methods and materials}

A quasi-experimental, nonequivalent comparison group design was used to assess patient satisfaction and the effects of demographics and health conditions together with patient consultations on their health conditions. The study was conducted in 2004 over an eight-month period in British Columbia, Canada. Ethics approval had been previously obtained through the University of British Columbia's Office of Research Services.

\section{Participants}

Patients throughout British Columbia frequenting APPEaffiliated community pharmacies (national chains and independently owned) during the period of the study were invited to complete a streamlined PC-based survey. Pharmacies were located throughout the entire province and in both urban and rural settings proportionate to the province's overall population demographics. Project staff deposited bundles of blank surveys at participating pharmacies together with survey return boxes. Pharmacists and students were instructed to hand surveys to all patients filling or refilling prescriptions and to encourage them to complete the surveys and to deposit them in the survey return box which was labeled to assure patients that their responses would be delivered directly to the research project office without being read by pharmacy personnel.

\section{Data collection}

The survey asked 15 questions representing the six PC domains described by Cipolle et al (developing a relationship, assessing patients, clarifying the role of medications, developing a pharmacy care plan, working collaboratively with other health care providers, and providing follow-up to patients). ${ }^{3}$ Questions were phrased as service delivery features and asked patients about their expectations regarding PC-related activities while shopping in any pharmacy and an additional parallel 15 questions about their experiences while shopping in this particular pharmacy. Responses were recorded using five-point Likert letter scales of disagreement/ agreement, ie, strongly disagree, disagree, neutral, agree, and strongly agree. The pilot study had earlier demonstrated that the scale has strong reliability and validity. The overall expectation index had a Cronbach reliability of $\alpha=0.89$, while the in-store experience reliability was $\alpha=0.94$. As before, the survey also collected brief demographic data, but included new information regarding pharmacist/student consultations on a variety of medical conditions following their satisfaction reports. A research assistant entered all the data into Excel spreadsheets.

\section{Analysis}

Descriptive statistics (frequencies, means, and standard deviations) from the new study participants were summarized. Robustness and sensitivity were both tested as fractions of variance accounted for Pearson's $r^{2}$ or $\eta^{2}$ by demographic or store factors. New factor analyses were carried out and from the factor structures, scale and subscale scores operationalized patient satisfaction measures. For the respondents, paired $t$-tests were used to compare baseline expectations in any pharmacy with in-store experience on individual satisfaction items, subscale scores, and overall scale score. Scores indicating "service gaps" were computed as the difference between expectation and experience. For ease of interpretation, all computed subscale and overall scores as well as gap scores were transformed into scales ranging from 1 to 5 , and parallel to the original response formats.

Four levels of consultation were categorized, ie, none, student only, pharmacist only, or both student and pharmacist. Responses to expectations and experiences were compared for these four consultation groups using one-way analysis of variance and post hoc comparisons. Similar procedures were used to compare service gap scores across consultation groups and demographic factors. Throughout, statistical analyses were conducted using SPSS 17.0 for Windows (SPSS Inc, Chicago, IL).

\section{Results}

\section{Respondents}

A total of 628 patients from 55 community pharmacy stores representing national chains and independent pharmacies returned completed surveys. No precount of surveys was maintained; therefore, response rates cannot be determined. 
The patient sample included $37 \%$ males and $63 \%$ females. All age groups, education levels, and household incomes were well represented. Table 1 summarizes the demographic characteristics of the respondents. Most were mature, ie, in the 40-60-year or 60-80-year age brackets with "some college or university" education levels, and household incomes averaging just under $\$ 50,000$ annually.

Patients were asked whether they had received consultations lasting at least 15 minutes for any of seven medical conditions (asthma, diabetes, heart condition, blood pressure, cholesterol, arthritis, osteoporosis, and "other") and whether consultations had occurred with an in-store pharmacist, a pharmacy student, both, or neither. Table 1 reports these

Table I Demographic characteristics and frequency of consultation about medical condition for the total sample

\begin{tabular}{|c|c|}
\hline Total $n=628$ & Percent $^{a}$ (n) \\
\hline \multicolumn{2}{|l|}{ Gender } \\
\hline Male & $36.9 \%(223)$ \\
\hline Female & $63.1 \%(38 I)$ \\
\hline \multicolumn{2}{|l|}{ Age, years } \\
\hline Under 40 & $16.4 \%(96)$ \\
\hline 40 to 59 & $36.3 \%(213)$ \\
\hline 60 to 79 & $40.4 \%(237)$ \\
\hline 80 or over & $6.8 \%(40)$ \\
\hline \multicolumn{2}{|l|}{ Education } \\
\hline Grade school & $8.2 \%(46)$ \\
\hline High school graduate & $27.5 \%(154)$ \\
\hline Some college/university & $30.2 \%(169)$ \\
\hline College/university graduate & $25.5 \%(143)$ \\
\hline Post-graduate degree & $8.6 \%(48)$ \\
\hline \multicolumn{2}{|l|}{ Household income } \\
\hline Under $\$ 10,000$ & II.I\% (55) \\
\hline$\$ 10,000$ to $\$ 29,999$ & $22.4 \%(111)$ \\
\hline$\$ 30,000$ to $\$ 49,999$ & $32.3 \%(160)$ \\
\hline$\$ 50,000$ to $\$ 99,999$ & $26.3 \%(130)$ \\
\hline$\$ 100,000$ or over & $7.9 \%(39)$ \\
\hline \multicolumn{2}{|l|}{ Number of pharmacies participating } \\
\hline National chains & $74.5 \%(468)$ \\
\hline Independents & $25.5 \%(160)$ \\
\hline \multicolumn{2}{|l|}{ Had consultation for medical condition } \\
\hline Blood pressure & $23.7 \%(149)$ \\
\hline Cholesterol & $15.8 \%(99)$ \\
\hline Heart condition & $14.8 \%(93)$ \\
\hline Diabetes & $14.3 \%(90)$ \\
\hline Asthma & $12.9 \%(8 I)$ \\
\hline Arthritis & $9.9 \%(62)$ \\
\hline Osteoporosis & $8.6 \%(54)$ \\
\hline Other (multiple responses are possible) & $18.0 \%(113)$ \\
\hline \multicolumn{2}{|l|}{ Who was consultation with } \\
\hline No consultation & $61.2 \%(284)$ \\
\hline Pharmacist only & $10.6 \%(49)$ \\
\hline Student only & $11.4 \%(53)$ \\
\hline Both pharmacist and student & $16.8 \%(78)$ \\
\hline
\end{tabular}

Note: ${ }^{\text {Reported as valid percentages due to missing data for some variables and } \mathrm{n}}$ does not equal 628 . medical conditions. About a quarter of the patients did not answer the consultation question. Of the 464 patients (73.9\%) who did report, the majority (61\%) had had no consultation, while $11 \%$ each had consulted with a pharmacist only or a student only; $17 \%$ reported a consultation with both pharmacist and student. About one-quarter (24\%) of patients reported consultations about blood pressure, while cholesterol, heart conditions, diabetes, and asthma were each discussed for about $15 \%$ of patients (Table 1 ).

\section{Anchored satisfaction measures}

Overall, the current study expanded by more than four-fold the numbers of respondents in the pilot study, nearly tripled the numbers of pharmacies, and doubled the numbers of chains represented. The expanded numbers and demographic ranges of respondents enabled a more definitive examination of the benefits of contrasting patient experiences in a particular pharmacy against what they would expect in any pharmacy. For all 15 items, the average respondent either "agreed" or "strongly agreed" that they would expect that feature in any pharmacy. But what they actually experienced in this particular pharmacy averaged nearly a half point lower for all items combined. Further, for all items but one, scores for the in-store experience were higher than the mid-scale "neutral/don't care" rating.

Table 2 reports these item-by-item figures in descending order of the differences between expectations and experiences, or "service gaps". The greatest shortfalls appear for shared decision-making responsibilities, collaboration among pharmacists, physicians, and patients, discussing different available options, and inquiring regarding concerns about medications. For only one item did overall patient experiences outperform expectations, ie, pleasant and courteous staff. And for only that single item was the difference nonsignificant; the shortfalls for all remaining 14 items were statistically significant $(P<0.001)$. Further, shortfall differences for the overall scale and its three factorially derived subscales were also statistically significant $(P<0.001)$.

\section{Factorial corroboration}

New factor analyses were undertaken to compare the pilot study's "expect anywhere" factor structures. ${ }^{18}$ Previously, three factors were identified, which explained $60 \%$ of the common factor variance, ie, monitoring outcomes (five items), providing information and education (five items), and giving personalized, collaborative, and preventive care (five items). 
Table 2 Comparison of baseline expectations in any pharmacy with in-store experience $(n=628)$

\begin{tabular}{|c|c|c|c|}
\hline $\begin{array}{l}\text { (Item no) Abbreviated }{ }^{a} \text { satisfaction questions } \\
\text { (descending order of difference scores) }\end{array}$ & $\begin{array}{l}\text { Baseline expectation } \\
\text { (mean } \pm \text { SD) }\end{array}$ & $\begin{array}{l}\text { In-store experience } \\
\text { (mean } \pm \text { SD) }\end{array}$ & $\begin{array}{l}\text { Difference }=\text { in-store baseline } \\
(\text { mean } \pm \text { SD) }\end{array}$ \\
\hline (4) Share decision-making responsibilities & $4.44 \pm 0.72$ & $3.68 \pm 1.06$ & $-0.76 \pm 1.09$ \\
\hline (I2) Work with doctor and me to ensure best medications & $4.21 \pm 0.87$ & $3.63 \pm 1.08$ & $-0.59 \pm 1.11$ \\
\hline (8) Discuss different medical options available & $4.03 \pm 0.93$ & $3.47 \pm 1.11$ & $-0.57 \pm 1.13$ \\
\hline (3) Ask if I have any concerns about my medications & $4.39 \pm 0.68$ & $3.90 \pm 1.00$ & $-0.50 \pm 1.07$ \\
\hline (5) Ask about my existing medical conditions & $3.99 \pm 0.92$ & $3.56 \pm 1.08$ & $-0.45 \pm 1.01$ \\
\hline (14) Explain how to know if medications are working & $4.05 \pm 0.90$ & $3.62 \pm 1.10$ & $-0.43 \pm 1.10$ \\
\hline (2) Reasonable privacy for discussions & $4.59 \pm 0.58$ & $4.17 \pm 0.91$ & $-0.42 \pm 1.06$ \\
\hline (I0) Develop a written care plan & $3.77 \pm 1.01$ & $3.35 \pm 1.11$ & $-0.42 \pm 1.16$ \\
\hline (7) Ask me questions about my various medications & $4.05 \pm 0.88$ & $3.65 \pm 1.10$ & $-0.41 \pm 1.08$ \\
\hline (I3) Explain what to do if side effects occur & $4.41 \pm 0.73$ & $4.01 \pm 0.97$ & $-0.40 \pm 1.03$ \\
\hline (6) Ask how well medical conditions are controlled & $3.85 \pm 0.93$ & $3.47 \pm 1.10$ & $-0.37 \pm 1.00$ \\
\hline (II) Offer variety of info sources; print, video, verbal & $3.83 \pm 0.83$ & $3.48 \pm 1.04$ & $-0.36 \pm 1.05$ \\
\hline (9) Explain how each medication is supposed to work & $4.23 \pm 0.81$ & $4.03 \pm 0.98$ & $-0.21 \pm 1.01$ \\
\hline (I5) Phone ask between refills if medications are working & $3.00 \pm 1.08$ & $2.79 \pm 1.18$ & $-0.20 \pm 1.10$ \\
\hline (I) Pleasant and courteous pharmacy staff & $4.68 \pm 0.51$ & $4.73 \pm 0.55$ & $+0.04 \pm 0.66$ \\
\hline Scale: Monitoring outcomes & $3.72 \pm 0.76$ & $3.37 \pm 0.98$ & $-0.36 \pm 0.81$ \\
\hline Scale: Information and education & $4.07 \pm 0.64$ & $3.66 \pm 0.85$ & $-0.42 \pm 0.79$ \\
\hline Scale: Personalized, collaborative and preventive care & $4.53 \pm 0.45$ & $4.12 \pm 0.68$ & $-0.4 \mathrm{I} \pm 0.7 \mathrm{I}$ \\
\hline Overall score (mean of all I5 items) & $4.10 \pm 0.54$ & $3.71 \pm 0.78$ & $-0.40 \pm 0.69$ \\
\hline
\end{tabular}

Note: ${ }^{\text {Refer }}$ to Table 3 for complete questions.

Abbreviation: SD, standard deviation.

In this updated analysis, a principal component three-factor solution with equamax rotations (Kaiser-Meyer-Olkin $=0.88$ ) again explained $60 \%$ of the variance, with 11 of the 15 items loading on the three factors in the same ways as in the pilot study (see Table 3). Two items shared their variance across two factors each, and two items loaded on different factors. Based on these results and slight improvements in interpretability, the revised factor structure is: monitoring outcomes, consisting of items 5, 6, 7, and 15; providing information and education, consisting of items $8,9,10,11,12,13$, and 14 ; and giving personalized, collaborative and preventive care, consisting of items 1, 2, 3, and 4. Similarly, factor analysis of the "experienced in this store" items yielded three factors (Kaiser-Meyer-Olkin $=0.92$ ) accounting for $68 \%$ of the common factor variance and loading on the same three factors, although in slightly different order. In both analyses, all 15 items loaded on the first unrotated component confirming that there is a single generalized "satisfaction factor" and in both instances, equamax rotations resulted in more interpretable solutions than varimax.

For the three subscales created from the factor structure, reliability analysis yielded the following Cronbach's alphas: monitoring outcomes, $\alpha=0.81$; information and education, $\alpha=0.86$; and personalized, collaborative and preventive care, $\alpha=0.70$. All were very similar to the values reported in the pilot study and all met or exceeded Nunnally's threshold of 0.70 . For the overall satisfaction scale consisting of all 15 items, $\alpha=0.90 .^{26}$

\section{Generalizabiity, robustness, and sensitivity}

Robustness and sensitivity are reciprocal concepts both embedded within generalizability. Robustness presumes that satisfaction scale measurements are not biased by attributes they are not intended to measure, such as gender, age, education, income, or disease type. Sensitivity, on the other hand, means that satisfaction scales do represent true variations in customer reports of stores which deliver better PC services than weaker stores, or chains which have overall patterns of better service delivery than others, or locations with better consultation practices than others.

The upper portion of Table 4 shows that the overall satisfaction scale, its three subscales, and service gaps are generally robust across different patient demographics, different disease types, different chains, and different pharmacy outlets. Mean gap scores were not significantly different across gender, income, or age (although the $80+$ group reported lower gaps). Weakly significant differences $(0.01<P<0.05)$ were noted across levels of education, with higher education (especially those with post-graduate training) leading to greater gap scores. Consultation was more effective at reducing service gaps for asthma, diabetes, heart conditions, and blood pressure issues, 
Table 3 Factor $^{\mathrm{a}}$ loadings of 15 "expectation" items, sorted according to descending loading by factor

\begin{tabular}{|c|c|c|c|}
\hline $\begin{array}{l}\text { (Item no) complete satisfaction questions: } \\
\text { here is what I would expect in any pharmacy }\end{array}$ & $\begin{array}{l}\text { Factor I: monitoring } \\
\text { outcomes }\end{array}$ & $\begin{array}{l}\text { Factor 2: information } \\
\text { and education }\end{array}$ & $\begin{array}{l}\text { Factor 3: personalized, } \\
\text { collaborative, and } \\
\text { preventive care }\end{array}$ \\
\hline $\begin{array}{l}\text { (A6) I expect pharmacists to ask me how well medical } \\
\text { conditions are controlled }\end{array}$ & 0.79 & & \\
\hline $\begin{array}{l}\text { (A5) I expect pharmacists to ask me questions about } \\
\text { my existing medical conditions }\end{array}$ & 0.78 & & \\
\hline $\begin{array}{l}\text { (A7) I expect pharmacists to ask me questions about } \\
\text { the various medications I take }\end{array}$ & 0.77 & & \\
\hline $\begin{array}{l}\text { (A8) I expect pharmacists to discuss the different choices } \\
\text { of medications available to treat my conditions }\end{array}$ & 0.55 & 0.48 & \\
\hline $\begin{array}{l}\text { (AI4) I expect pharmacists to explain to me how to know } \\
\text { for sure if my medications are working }\end{array}$ & & 0.80 & \\
\hline (AI3) I expect pharmacists to explain what to do in case & & 0.73 & \\
\hline I have side effects from my medications & & & \\
\hline $\begin{array}{l}\text { (A I0) I expect pharmacists to develop a specific plan to } \\
\text { solve any problem I may be having with my medications }\end{array}$ & & 0.72 & \\
\hline $\begin{array}{l}\text { (AI2) I expect pharmacists to work with doctor and me } \\
\text { to ensure I am on the right medications }\end{array}$ & & 0.67 & \\
\hline $\begin{array}{l}\text { (A9) I expect pharmacists to explain how each of my } \\
\text { medications is supposed to help me }\end{array}$ & & 0.67 & \\
\hline $\begin{array}{l}\text { (Al I) I expect pharmacists to offer me a choice } \\
\text { of information sources; print, video, verbal }\end{array}$ & & 0.58 & \\
\hline $\begin{array}{l}\text { (AI5) I expect pharmacists to phone me or ask me } \\
\text { between refills whether my medications are working }\end{array}$ & 0.44 & 0.55 & \\
\hline $\begin{array}{l}\text { (A2) I expect reasonable privacy when I discuss } \\
\text { my health issues with a pharmacist }\end{array}$ & & & 0.78 \\
\hline $\begin{array}{l}\text { (Al) I expect pharmacy staff to be pleasant and } \\
\text { courteous to me }\end{array}$ & & & 0.75 \\
\hline $\begin{array}{l}\text { (A3) I expect pharmacists to ask me if I have any } \\
\text { concerns about my medications }\end{array}$ & 0.53 & & 0.54 \\
\hline $\begin{array}{l}\text { (A4) I expect pharmacists to involve me when it } \\
\text { comes to making decisions about my medications }\end{array}$ & 0.44 & & 0.45 \\
\hline
\end{tabular}

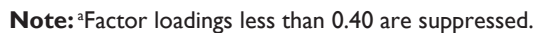

and less so for cholesterol concerns, arthritis, and osteoporosis. Only minimal fractions of the scales' variances (usually less than $1 \%-2 \%$ ) can be attributed to any of these demographic or health conditions. In contrast, the table's lower portion shows that the scales are highly sensitive to customer reports of satisfaction with the different pharmacies $(20 \%+)$, to the impact of in-store consultations (10\%-20\%), and less so with the pharmacy's affiliation to a specific chain or independent ownership (4\%). Thus, these PC-based scales of satisfaction are instances of well developed scales which are sensitive to the attributes they are intended to measure, but robust against extraneous "noise".

\section{In-store consultations}

Patient in-store satisfaction differed greatly depending on patient experiences with in-store consultations (Table 5). Of those reporting, and compared with those who received no consultation, satisfaction was significantly greater for groups who reported consultation with both pharmacists and students $(P<0.001)$ or with pharmacists alone $(P<0.001)$. Consultation with a student alone also showed higher mean satisfaction, but the differences were not statistically significant. Still, patient consultations were the exception not the rule; 284 reported no consultations and 164 skipped the question and can be presumed to have received no consultation, so consultations by students are not yet a general feature of patient interactions in stores adopting PC-based philosophies and practices.

Similarly, service gaps (Table 6) between what was expected and what was experienced was widest for no consultation, narrower for student-only consultations, and still narrower for pharmacist-only consultations. However, for student-plus-pharmacist consultations $(\mathrm{n}=78)$, patients on average reported greater overall in-store satisfaction than they would have expected in any pharmacy, hence the gap reversal was not a deficit but rather an asset. 
Table 4 Robustness and sensitivity of pharmaceutical care-based satisfaction scales for demographic, health, and store characteristics

\begin{tabular}{|c|c|c|c|c|c|c|c|c|c|c|}
\hline & \multicolumn{2}{|c|}{$\begin{array}{l}\text { Overall } \\
\text { satisfaction }\end{array}$} & \multicolumn{2}{|c|}{$\begin{array}{l}\text { Monitoring } \\
\text { outcomes }\end{array}$} & \multicolumn{2}{|c|}{$\begin{array}{l}\text { Providing } \\
\text { information } \\
\text { and education }\end{array}$} & \multicolumn{2}{|c|}{$\begin{array}{l}\text { Personalized, } \\
\text { collaborative } \\
\text { and preventive care }\end{array}$} & \multicolumn{2}{|c|}{ Service gaps } \\
\hline & ror $\eta^{a}$ & $\%^{\mathrm{b}}$ & ror $\eta^{a}$ & $\%^{\mathrm{b}}$ & ror $\eta^{a}$ & $\%^{\mathrm{b}}$ & ror $\eta^{a}$ & $\%^{\mathrm{b}}$ & ror $\eta^{a}$ & $\%^{\mathrm{b}}$ \\
\hline \multicolumn{11}{|l|}{ Robustness } \\
\hline Gender & -0.03 & 0.10 & -0.07 & 0.40 & -0.04 & 0.20 & 0.03 & 0.10 & -0.00 & 0.00 \\
\hline Age & $0.09^{c}$ & 0.80 & $0.085^{c}$ & 0.70 & $0.102^{c}$ & 1.0 & 0.053 & 0.20 & 0.07 & 0.50 \\
\hline Education & $-0.14^{c}$ & 1.90 & $-0.16^{c}$ & 2.60 & $-0.15^{c}$ & 2.10 & -0.08 & 0.60 & $-0.12^{c}$ & 1.30 \\
\hline Income & -0.06 & 0.30 & -0.08 & 0.60 & -0.05 & 0.20 & -0.02 & 0.00 & -0.01 & 0.00 \\
\hline Medical condition & $0.10^{c}$ & 0.10 & $0.11^{c}$ & 0.10 & $0.092^{c}$ & 0.10 & $0.082^{c}$ & 0.10 & -0.07 & 0.00 \\
\hline Number of conditions & -0.10 & 0.90 & 0.09 & 0.80 & 0.11 & 1.10 & 0.00 & 0.00 & -0.08 & 0.50 \\
\hline \multicolumn{11}{|l|}{ Sensitivity } \\
\hline Different chains & $0.21^{\mathrm{c}}$ & 4.50 & 0.210 & 4.30 & $0.20^{c}$ & 4.10 & $0.20^{c}$ & 3.80 & $0.21^{c}$ & 4.50 \\
\hline Different stores & $0.5 \mathrm{I}^{\mathrm{c}}$ & 25.60 & $0.52^{c}$ & 26.80 & $0.49^{c}$ & 23.70 & $0.47^{c}$ & 21.90 & $0.49^{c}$ & 23.60 \\
\hline Consultations & $0.44^{c}$ & 18.20 & $0.44^{c}$ & 18.50 & $0.42^{c}$ & 17.40 & $0.32^{c}$ & 10.20 & $0.36^{c}$ & 12.50 \\
\hline
\end{tabular}

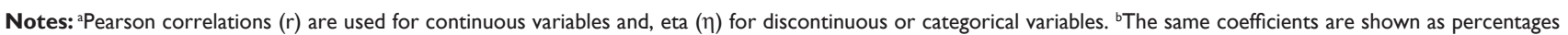
of satisfaction accounted for by gender, age, medical condition, chain, or store. ${ }^{c} p<0.05$.

Tests for gender differences in service gaps showed essentially the same pattern for both male and female patients: highest gaps when no consultation occurred, slightly lower gaps for consultation with student only, much lower gaps for pharmacist only, and greater than expected satisfaction for consultations with both pharmacist and student.

Similar patterns emerged for subgroups based on age, education, and income groups, with the following exceptions. For the $80+$ age group, which overall reported lower gaps, it did not seem to matter who the consultation was with, ie, student or pharmacist or both, and simply having a consultation reduced the service gap. Consultation effects were also lower for the "post-graduate" education group and the "over $\$ 100,000$ " income group. The absence of significant differences among consultation levels may be due to smaller effects or to small samples. Nor was there any association between disease type and consultation patterns.

\section{Service gaps}

Service gap information offers a quick and helpful diagnostic tool for store managers to learn which PC-related features of their stores are functioning properly and which features need attention. Few stores function perfectly, but information from this broad sample of stores, patients, chains, and demographics provides some baseline information about what is reasonable to expect and where the most common sources of patient dissatisfaction lie.

Overall, service gap scores (Figure 1) across the 55 pharmacies ranged from 1.39 (seriously under-performing, to the right) to -0.42 (better than expected, to the left) with an average of 0.46 (about a half point lower than would be expected in any store). Of course, any one patient might provide either highly complementary $(-1.80)$ or seriously critical (3.33) reports of their in-store experiences, but stores averaged about a dozen reports each (ranging from only 1-2 reports to as many as 40), so most stores' service gap scores represents a consensus of many patient reports. Of the 55 pharmacies in the study, only six performed at or above overall expectation. The mean gap between expected and experienced was 0.46 and the mode was 0.44 , suggesting that about a half point of shortfall might be tolerated. But for stores with shortfalls in the $0.60 \mathrm{~s}, 0.70 \mathrm{~s}, 0.80 \mathrm{~s}$, and beyond, one or more things must be seriously amiss and managers have a responsibility to identify and correct the problems.

A closer inspection of 17 pharmacies (31\%) representing 157 patients with service gaps of 0.60 or more revealed the following specific problems in descending order of severity: failing to share decision-making responsibilities, failing to discuss different treatment options available, failing to develop a written care plan, failing to explain what to do if side effects appear, failing to work with doctor and patient to ensure the best medications, and failing to ask about existing medical conditions. Slightly less critical were these four; failing to explain how to know if medications are working, failing to ask questions about various medications, failing to ask how well medical conditions are controlled, and failing to ask regarding any concerns about medications. Not surprisingly, patients in these pharmacies also reported disproportionately small numbers of consultations; studentonly $3 \%$, pharmacist-only $6 \%$, both student and pharmacist $6 \%$, and no consultation at all $65 \%$ (compared with $48 \%$ for the total sample of 55 stores). 


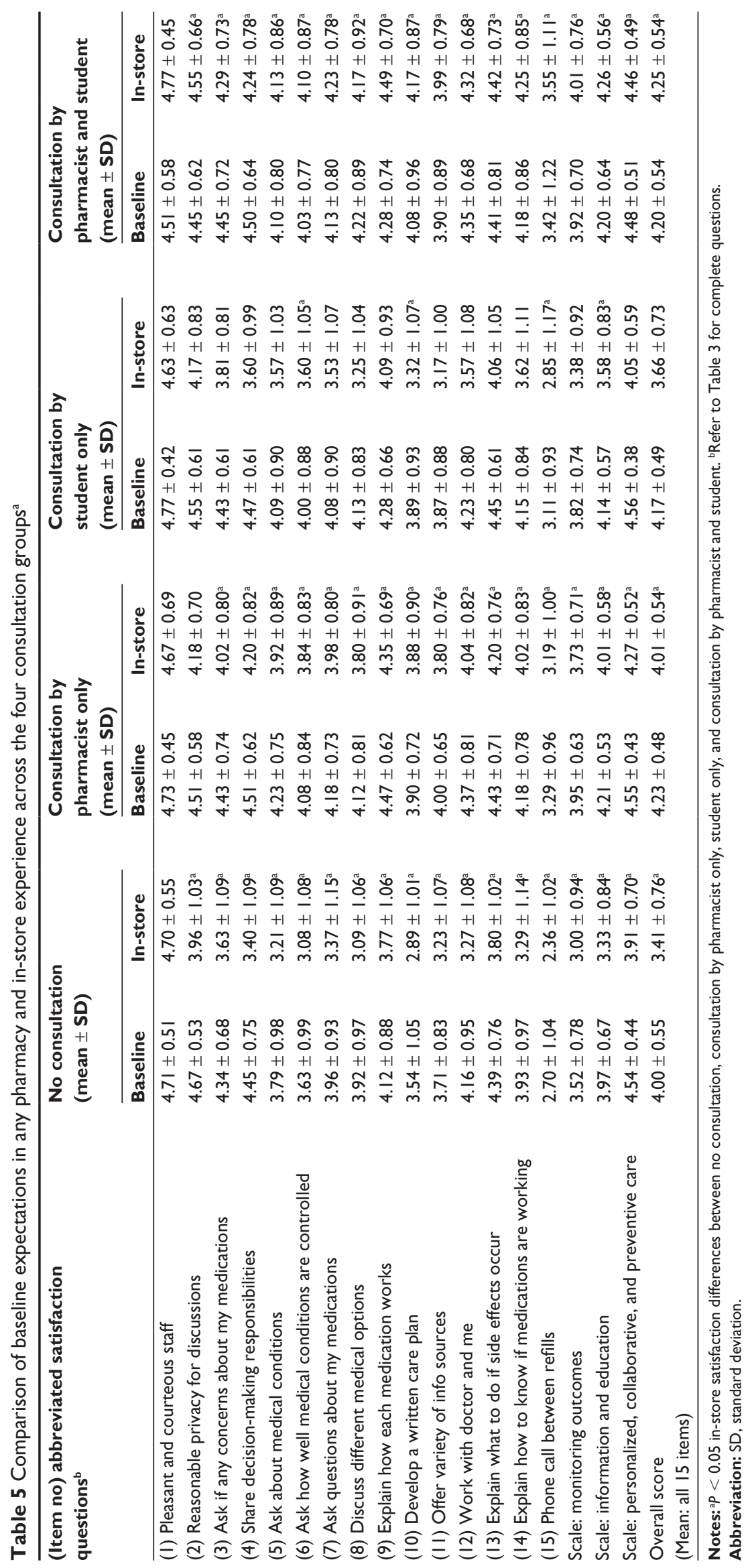


Table 6 Effect of consultation on mean service gap scores (this store minus any store)

\begin{tabular}{|c|c|c|c|c|}
\hline $\begin{array}{l}\text { (Item no) abbreviated satisfaction } \\
\text { questions }^{\mathrm{b}}\end{array}$ & $\begin{array}{l}\text { No consultation } \\
\text { (mean } \pm \text { SD) }\end{array}$ & $\begin{array}{l}\text { Consultation by } \\
\text { pharmacist only } \\
\text { (mean } \pm \text { SD) }\end{array}$ & $\begin{array}{l}\text { Consultation by } \\
\text { student only } \\
\text { (mean } \pm \text { SD) }\end{array}$ & $\begin{array}{l}\text { Consultation by } \\
\text { pharmacist and student } \\
\text { (mean } \pm \text { SD) }\end{array}$ \\
\hline (I) Pleasant and courteous pharmacy staff & $-0.02 \pm 0.66$ & $-0.06 \pm 0.77$ & $-0.13 \pm 0.69$ & $0.26 \pm 0.67^{\mathrm{a}}$ \\
\hline (2) Reasonable privacy for discussions & $-0.71 \pm 1.15^{\mathrm{a}}$ & $-0.33 \pm 0.83^{\mathrm{a}}$ & $-0.38 \pm 0.86^{\mathrm{a}}$ & $0.10 \pm 0.82$ \\
\hline (3) Ask if I have any concerns about my medications & $-0.70 \pm 1.15^{\mathrm{a}}$ & $-0.41 \pm 1.08^{a}$ & $-0.62 \pm 0.88^{a}$ & $-0.20 \pm 0.93$ \\
\hline (4) Share decision-making responsibilities & $-1.06 \pm 1.18^{\mathrm{a}}$ & $-0.31 \pm 0.77^{\mathrm{a}}$ & $-0.87 \pm 1.00^{\mathrm{a}}$ & $-0.26 \pm\left. 0.9\right|^{\mathrm{a}}$ \\
\hline (5) Ask about my existing medical conditions & $-0.62 \pm 1.02^{\mathrm{a}}$ & $-0.33 \pm 0.88^{\mathrm{a}}$ & $-0.53 \pm 1.08^{\mathrm{a}}$ & $0.03 \pm 0.94$ \\
\hline (6) Ask how well medical conditions are controlled & $-0.55 \pm 1.0 \mathrm{I}^{\mathrm{a}}$ & $-0.24 \pm 1.03$ & $-0.38 \pm 0.89^{a}$ & $0.08 \pm 0.89$ \\
\hline (7) Ask me questions about my various medications & $-0.59 \pm 1.17^{\mathrm{a}}$ & $-0.20 \pm 0.76$ & $-0.55 \pm 1.14^{\mathrm{a}}$ & $0.12 \pm 0.79$ \\
\hline (8) Discuss different medical options available & $-0.84 \pm 1.17^{\mathrm{a}}$ & $-0.33 \pm 0.85^{\mathrm{a}}$ & $-0.89 \pm 1.09^{a}$ & $-0.05 \pm 0.98$ \\
\hline (9) Explain how each medication is supposed to work & $-0.36 \pm 1.1 \mathrm{I}^{\mathrm{a}}$ & $-0.12 \pm 0.70$ & $-0.19 \pm 1.06$ & $0.21 \pm 0.82^{\mathrm{a}}$ \\
\hline (10) Develop a written care plan & $-0.65 \pm 1.1 \mathrm{I}^{\mathrm{a}}$ & $-0.04 \pm 0.85$ & $-0.57 \pm 1.12^{\mathrm{a}}$ & $0.12 \pm 1.26$ \\
\hline (II) Offer variety of information sources; print, video, verbal & $-0.5 \mathrm{I} \pm 1.08^{\mathrm{a}}$ & $-0.20 \pm 0.74$ & $-0.70 \pm 1.14^{\mathrm{a}}$ & $0.11 \pm 0.99$ \\
\hline (I2) Work with doctor and me to ensure best medications & $-0.90 \pm 1.15^{\mathrm{a}}$ & $-0.33 \pm 0.94^{\mathrm{a}}$ & $-0.66 \pm 1.21^{\mathrm{a}}$ & $-0.01 \pm 0.89$ \\
\hline (13) Explain what to do if side effects occur & $-0.59 \pm 1.09^{a}$ & $-0.22 \pm 0.87$ & $-0.40 \pm 1.0 \mathrm{I}^{\mathrm{a}}$ & $0.01 \pm 1.01$ \\
\hline (14) Explain how to know if medications are working & $-0.64 \pm 1.10^{\mathrm{a}}$ & $-0.16 \pm 0.90$ & $-0.53 \pm 1.07^{a}$ & $0.06 \pm 0.88$ \\
\hline (I5) Phone ask between refills if medications are working & $-0.36 \pm 1.0 \mathrm{I}^{\mathrm{a}}$ & $-0.08 \pm 1.01$ & $-0.26 \pm 0.98$ & $0.14 \pm 1.37$ \\
\hline Scale: monitoring outcomes & $-0.55 \pm 0.77^{\mathrm{a}}$ & $-0.18 \pm 0.64$ & $-0.47 \pm 0.8 \mathrm{I}^{\mathrm{a}}$ & $0.10 \pm 0.75$ \\
\hline Scale: information and education & $-0.65 \pm 0.85^{\mathrm{a}}$ & $-0.23 \pm 0.52^{\mathrm{a}}$ & $-0.59 \pm 0.79^{a}$ & $0.06 \pm 0.65$ \\
\hline Scale: personalized, collaborative and preventive care & $-0.62 \pm 0.74^{\mathrm{a}}$ & $-0.27 \pm 0.52^{\mathrm{a}}$ & $-0.48 \pm 0.58^{\mathrm{a}}$ & $-0.01 \pm 0.58$ \\
\hline Overall score (mean of all I5 items) & $-0.60 \pm 0.7 \mathrm{I}^{\mathrm{a}}$ & $-0.22 \pm 0.46^{\mathrm{a}}$ & $-0.51 \pm 0.66^{\mathrm{a}}$ & $0.05 \pm 0.58$ \\
\hline
\end{tabular}

Notes: ${ }^{a} P<0.05$ differences between any store expectation and in-store experience; ${ }^{\text {RRefer to }}$ Table 3 for complete questions.

Abbreviation: SD, standard deviation.

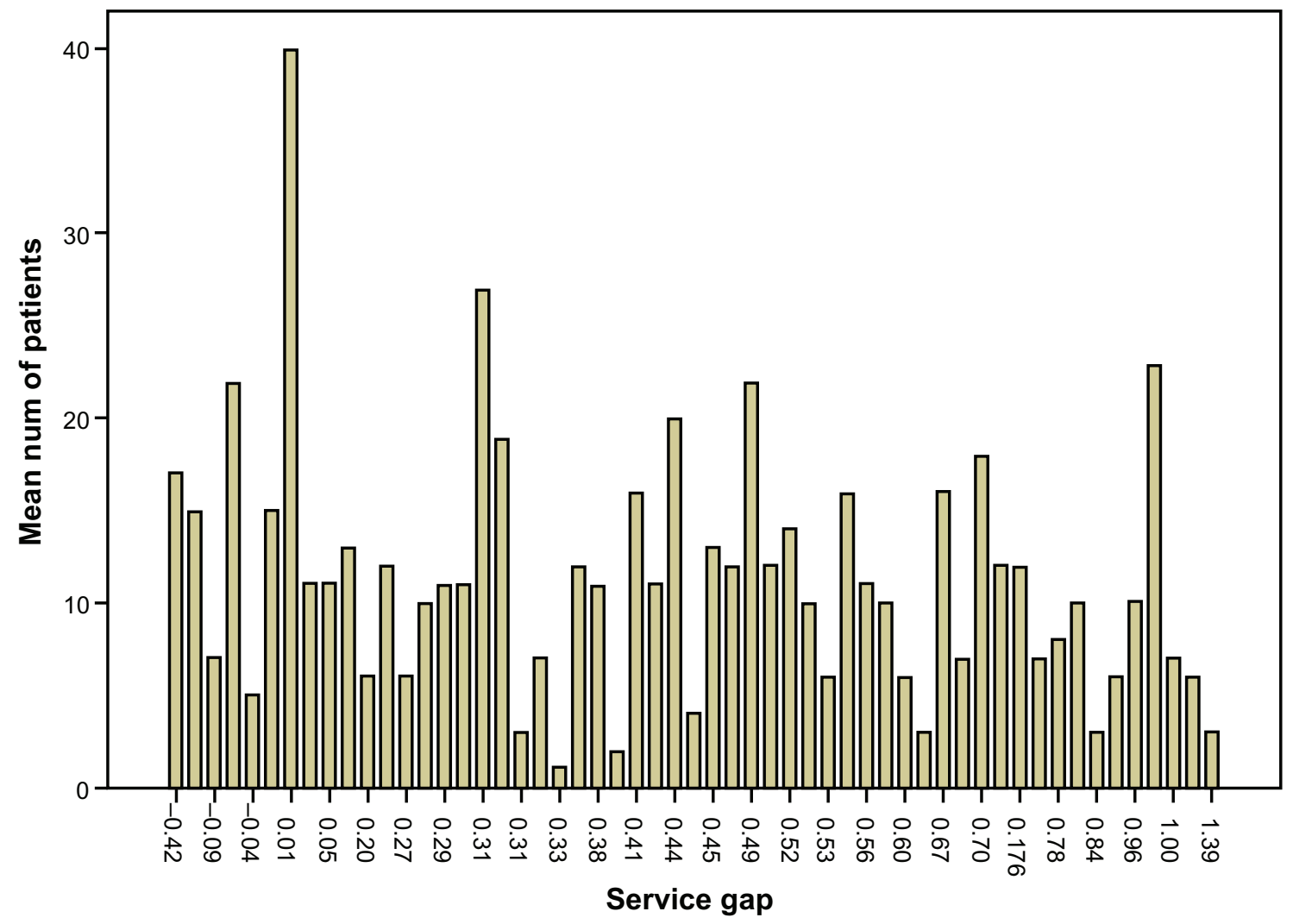

<-- Positive or minimal service gaps

Multiple gaps; seriously deficient -->

Figure I Service gaps for 55 community pharmacies. 
Overall, it appears that the common thread is failure to integrate the patient as part of the care team, an attitude of "do to" rather than "do with", and a failure to implement the foundational notions of PC. Further, overall service gaps of about a half point can likely be tolerated as stores and chains shift their operating philosophies to conform better to the principles of PC. However, for service gaps greater than a half point, corrective action on the part of store managers is probably warranted.

\section{Discussion}

This study's overall objectives were to solidify and extend the insights of the earlier proof-of-concept study, that patient satisfaction measures could be structured on and grounded in the principles of PC and to document patient satisfaction as an additional incentive for community pharmacy managers to implement more PC domains into their stores' practices. ${ }^{18}$ Previous researchers had employed varieties of other approaches, including: economic, clinical and humanistic, ${ }^{21}$ ideal referents versus market expectations; ${ }^{20}$ pleasurability; ${ }^{22}$ service experiences and medication management; ${ }^{27}$ provider contrasts $;{ }^{26}$ and managing therapy/friendly explanation factors. ${ }^{20-23,26,27}$ "Solidify and extend" was defined to mean: larger and more diverse patient and community pharmacies, wider patient demographics, more varied patient health conditions, more formal tests of robustness and sensitivity, impact of in-store consultation practices, and the managerial utility of corrective information from brief patient questionnaires.

Among survey developers, it is a known hazard that surveys on nearly any topic can be developed, administered, validated, and published. However, Messick raises the additional requirement of "consequential validity" and argues that developers must remain mindful of the consequences of decisions which their survey results will inform. ${ }^{28}$ Thus, this study was structured to provide information directly usable by store managers to guide improvements to pharmacy practices that could improve the delivery of services along one or more of the three PC-grounded dimensions of satisfaction, ie, monitoring outcomes, providing information and education (including consultations), and giving personalized, collaborative, and preventive care. The overall findings provide some important insights to researchers and managers alike:

- It is not sufficient to ask simply whether in-store services or practices are "satisfactory" in the abstract. Whether the patient's experience was satisfactory or not depends on what $\mathrm{s} / \mathrm{he}$ expected in the first place. Therefore, it is necessary to "anchor" the experience against the background of expectation.
- Certain PC features are more "expected" than others, ie, pleasant and courteous staff; reasonable privacy for discussions, shared decision-making responsibilities versus phone between refills to ask if medications are working, developing written care plans, and being asked how well medical conditions are being controlled.

- Similarly, certain in-store experiences generate more satisfaction agreement than others, ie, pleasant and courteous staff, reasonable privacy for discussions, explaining how each medication is supposed to work, explaining what to do if side effects occur versus phoning between refills to ask if medications are working, developing written care plans, and or discussing different medical options available.

- Thus pharmacists and managers are challenged to distinguish between what patients claim to want versus what conscientious PC practice mandates they should receive. They may not expect phone calls between refills to ask about medication effectiveness, nor 15-minute consultations about their medications, but the ground rules of PCbased practice require that both must occur. Similarly, with respect to information and education, $\mathrm{PC}$ entails providing patients with an explanation of how each of their medication is supposed to work or developing care plans with the patient. In short, care involves public education and changes to expectations that patients may not yet be aware of.

These PC-based measures of satisfaction have now been tested and shown to be robust, ie, unbiased regarding gender, age, education, income, and health conditions, but concurrently sensitive to existing conditions and practices within individual stores, to consultation practices, and (weakly) to differences of membership in various pharmaceutical chains. Managers and pharmacists now have solid evidence that such satisfaction surveys can be implemented in their stores and they can be expected to yield helpful insights about directions for improvement.

Within community pharmacies, the adoption of PC remains a work-in-progress, and mobilizing initiatives to implement all of its domains presents an ongoing challenge. Schools of pharmacy occupy an advantageous position because they train the next generation of pharmacists, train the pharmacists/preceptors who supervise APPE students on rotations, establish syllabus requirements, and outline the learning requirements of students while on APPE rotations, thereby shifting the operating ethics of what a patient's in-store experience ought to be. Even assessment of existing records or patient consultations to check for drug-related problems is not a universal practice in all pharmacies, nor is developing a care plan. Thus, these 
APPE students along with their trained preceptors, can be an important vector in improving the routine performance of the profession and enhancing the expectations of their patients. When APPE student requirements are corroborated by patient satisfaction reports, store managers have increased incentives to promote adoption of PC into daily practice.

Previous studies have demonstrated that providing PC consultation either by student alone, pharmacist alone, and student-pharmacist teams, all contribute to identifying, resolving, and preventing greater numbers of drug-related problems..$^{5-8,10-12}$ This study was unique in its aim to examine the impact of differences in pharmacy practice, providing PC or not, on patient satisfaction. The results confirm that providing PC by students alone, pharmacists alone, or teams of students and pharmacy preceptors results in improved patient satisfaction. However, a pivotal finding was that community pharmacies participating in PC-based APPE models which promote student-pharmacist collaborative PC may yield the greatest levels of patient satisfaction, such that the patient experiences actually surpass their expectations. This finding confirms earlier studies that APPE students can and do contribute positively to reducing drug-related problems in community pharmacy settings and provides a strong argument that participating in APPE can add value to both the community pharmacy and to its patients.

\section{Conclusion}

Patient satisfaction can be reliably measured by surveys structured around the principles of pharmaceutical care. The introduction of PC into routine community pharmacy operations improves patient satisfaction, especially when accompanied by formal consultations about their medical conditions. Service gap details indicated that store managers need to pay closer attention to: involving patients in decision-making about their medications, discussing the choices of medications available, working with doctors and patients to ensure correct medication, and consulting with patients about their existing medical conditions and concerns, and taking a more proactive and consultative role in patient health care.

\section{Acknowledgments}

We thank all the store managers who agreed to have their stores participate, thereby making this study possible. Additionally, we are indebted to the in-store pharmacists, APPE students, and their preceptors who encouraged patients to complete the surveys and to the patients who did so.

\section{Disclosure}

The authors report no conflicts of interest in this work. JC received consultancy fees for assistance with conception, design, and refinement of the survey. Both JC and JB received consultancy fees for analysis and interpretation of the study data.

\section{References}

1. American Council on Pharmaceutical Education. Accreditation Standards and Guidelines for the Professional Program in Pharmacy Leading to the Doctor of Pharmacy Degree, adopted January 15, 2006. Chicago, IL: American Council on Pharmaceutical Education; 2006. Available from: https://www.acpe-accredit.org/standards/default.asp. Accessed December 30, 2011.

2. Association of Faculties of Pharmacy of Canada. Educational Outcomes for First Professional Degree Programs in Pharmacy in Canada. Vancouver, BC: Association of Faculties of Pharmacy of Canada. Available at: http://www.ccapp-accredit.ca/obtaining_accreditation/ Accessed December 30, 2011.

3. Cipolle RJ, Strand LM, Morley PC. Pharmaceutical Care Practice: The Clinician's Guide. 2nd ed. New York, NY: McGraw Hill; 1998.

4. Chisholm-Burns MA, Kim LJ, Spivey CA. US pharmacists' effect as team members on patient care: systematic review and meta-analyses. Med Care. 2010;48(10):923-933.

5. Kassam R, Kwong M. An enhanced community advanced pharmacy practice experience model to improve patient care. Am J Pharm Educ. 2009;73(2):Article 25. Available from: http://www.ncbi.nlm.nih.gov/pmc/ articles/PMC2690893/pdf/ajpe25.pdf. Accessed December 30, 2011.

6. Cerulli J, Malone M. Women's health promotion within a community advanced pharmacy practice experience. Am J Pharm Educ. 2008;72:Article 25. Available from: http://www.ncbi.nlm.nih.gov/pmc/ articles/PMC2384200/pdf/ajpe25.pdf. Accessed December 30, 2011.

7. Reddick JB, Murphy JE. Evaluating the clinical interventions of students during clerkships using a cognitive services claim form. Am J Pharm Educ. 2000;64:38-43. http://archive.ajpe.org/legacy/pdfs/aj640107.pdf. Accessed March 29, 2012.

8. MacKinnon GE. III. Analysis of pharmacy student interventions collected via an Internet-based system. Am J Pharm Educ. 2003;67(3):Article 90. Available from: http://archive.ajpe.org/aj6703/ aj670390/aj670390.pdf. Accessed December 30, 2011.

9. Willink DP, Isetts BJ. Becoming "indispensable": developing innovative community pharmacy practices. J Am Pharm Assoc. 2005;45:376-386.

10. Turner CJ, Ellis S, Giles J, et al. A strategy to develop advanced pharmacy practice experiences. Am J Pharm Educ. 2007;71(3):Article 46. Available from: http://www.ncbi.nlm.nih.gov/pmc/articles/PMC1913299/pdf/ ajpe46.pdf. Accessed December 30, 2011.

11. Rodis JL, Legg JE, Casper KA. Partner for promotion: an innovative advanced community pharmacy practice experience. Am JPharm Educ. 2009;72(6):Article 134. Available from: http://www.ncbi.nlm.nih.gov/ pmc/articles/PMC2661166/pdf/ajpe134.pdf. Accessed December 30, 2011.

12. Dugan DB. Enhancing community pharmacy through advanced pharmacy practice experiences. Am J Pharm Educ. 2006;70(1):Article 21. Available from: http://www.ncbi.nlm.nih.gov/pmc/articles/ PMC1636895/pdf/ajpe21.pdf. Accessed December 30, 2011.

13. Zaremski DG, Boyer G, Vlasses PH. A survey of advanced community pharmacy practice experiences in the final year of the PharmD curriculum at the US colleges and schools of pharmacy. Am J Pharm Educ. 2005;69(1):Article 2. Available from: http://archive.ajpe.org/aj6901/ aj690102/aj690102.pdf. Accessed December 30, 2011.

14. Kassam R. Evaluation of pharmaceutical care opportunities within an advanced pharmacy practice experience. Am J Pharm Educ. 2006;70(3):49. Available from: http://www.ncbi.nlm.nih.gov/pmc/ articles/PMC1636962/pdf/ajpe49.pdf. Accessed December 30, 2011. 
15. Christensen DB, Farris KB. Pharmaceutical care in community pharmacies: practice and research in the US. Ann Pharmacother. 2006;40(7-8):1400-1406.

16. Chase P. Rethinking experiential education (or does anyone want a pharmacy student). Am J Pharm Educ. 2007;71(2):Article 27. Available from: http://www.ncbi.nlm.nih.gov/pmc/articles/PMC1858610/pdf/ ajpe27.pdf. Accessed December 30, 2011.

17. MacKinnon GE III. Documentation: a value proposition for pharmacy education and the pharmacy profession. Am J Pharm Educ. 2007;71(4):Article 73. Available from: http://archive.ajpe.org/view. asp?art=aj710473\&pdf=yes. Accessed December 30, 2011.

18. Kassam R, Collins JB, Berkowitz J. Developing anchored measures of patient satisfaction with pharmaceutical care delivery: experiences versus expectations. Patient Prefer Adherence. 2009;3:113-122. Available from: http:/www.dovepress.com/developing-anchoredmeasures-of-patient-satisfaction-with-pharmaceutic-a3035. Accessed December 30, 2011.

19. Kassam R, Collins JB, Berkowitz J. Comparison of patients' expectations and experiences at traditional pharmacies and pharmacies offering enhanced advanced pharmacy practice experiences. Am J Pharm Educ. 2010;74(5):Article 90. Available from: http:/www.ncbi.nlm.nih.gov/ pmc/articles/PMC2907855/pdf/ajpe90.pdf. Accessed December 30, 2011.

20. Kucukarslan S, Schommer JC. Patients' expectations and their satisfaction with pharmacy services. J Am Pharm Assoc. 2002;42:489-496.
21. Gourley GK, Gourley DR, Rigolosi ELM, Reed P, Solomon DK, Washington E. Development and validation of the pharmaceutical care satisfaction questionnaire. Am J Manag Care. 2001;7:461-466.

22. Oliver RL. A cognitive model of the antecedents and consequences of satisfaction decisions. J Marketing Res. 1980;17:460-469.

23. Larson LN, Rovers JP, MacKeigan LD. Patient satisfaction with pharmaceutical care: update of a validated instrument. J Am Pharm Assoc. 2002;42(1):44-50.

24. Cronbach LJ, Gleser GC, Nanda H, Rajaratnam N. The Dependability of Behavioral Measurements: Theory of Generalizability for Scores and Profiles. New York, NY: John Wiley; 1972.

25. Nunnally JC. Psychometric Theory. 2nd ed. New York, NY: McGraw-Hill; 1978.

26. PR Newswire. Pharmacy customers have higher expectations for short wait times. September 20, 2011. Available from: http://www. prnewswire.com/news-releases/jd-power-and-associates-reportspharmacy-customers-have-higher-expectations-for-short-wait-times130189098.html. Accessed December 30, 2011.

27. McCombs JS, Cody M, Besinque K, et al. Measuring the impact of patient counseling in the outpatient pharmacy setting: the research design of the Kaiser Permanente/USC patient consultation study. Clin Ther. 1995;17(6):1188-1206.

28. Messick S. Validity. In: Linn RL, editor. Educational Measurement. 3rd ed. New York, NY: Macmillan; 1989.
Patient Preference and Adherence

\section{Publish your work in this journal}

Patient Preference and Adherence is an international, peer-reviewed, open access journal focusing on the growing importance of patient preference and adherence throughout the therapeutic continuum. Patient satisfaction, acceptability, quality of life, compliance, persistence and their role in developing new therapeutic modalities and compounds to

\section{Dovepress}

optimize clinical outcomes for existing disease states are major areas of interest. This journal has been accepted for indexing on PubMed Central. The manuscript management system is completely online and includes a very quick and fair peer-review system. Visit http://www.dovepress.com/ testimonials.php to read real quotes from published authors. 